\title{
Correlation between CIELAB colour coordinates and malondialdehyde eqiuvalents in sausage with paprika stored under refrigerated conditions
}

\author{
É. Varga-Visi* 무, V. Kozma and A. Szabó
}

\begin{abstract}
Department of Physiology and Animal Health, Institute of Physiology and Nutrition, Hungarian University of Agriculture and Life Sciences Kaposvár Campus, Guba S. u. 40, H-7400, Kaposvár, Hungary
\end{abstract}

\section{ORIGINAL RESEARCH PAPER}

\section{ABSTRACT}

Sensory properties of foods mainly affect purchasing decisions. In case of sausages, deterioration of pigments of meat and spices cause discolouration, while lipid oxidation leads to the formation of off-odours, and these two processes are connected. Lipid oxidation promotes the conversion of pigments, while the formation of metmyoglobin accelerates lipid oxidation. The scope of the study was to investigate the relationship between the amount of malondialdehyde equivalents (MDA) and CIELAB colour coordinates in a Hungarian sausage with paprika, sliced and stored under refrigerated conditions for 10 weeks. We detected negative correlation $(P<0.001)$ between the MDA-level and $\mathrm{a}^{*}$ and $\mathrm{b}^{*}$; and positive correlation $(P<0.001)$ between the MDA-level and $\mathrm{L}^{*}$. The observed correlation between MDA level and colour coordinates supports the assumption that the oxidation of lipids and pigments are interrelated in the case of sausage with paprika.

\section{KEYWORDS}

lipid oxidation, colour, sausage, paprika, thiobarbituric acid, malondialdehyde

\footnotetext{
*Corresponding author. Tel.: +3682505800/2307. E-mail: vargane.visi.eva@uni-mate.hu
} 


\section{INTRODUCTION}

Customers' acceptance is largely depending on the organoleptic properties of food products. In the case of meat products, the main cause of the quality decay, beside microbiological spoilage, is lipid oxidation, which leads to the formation of rancid odour and flavour (Domínguez et al., 2019). Meat discolouration is caused mainly by the conversion of oxymyoglobin to metmyoglobin (Faustman et al., 2010). These two processes, causing adverse effect to quality of meat products, are not independent of each other. Lipid oxidation is interconnected with the degradation of heme pigments. Oxidation of heme pigments accelerates lipid oxidation, while the formation of some lipid oxidation products can promote the unfavourable conversion of pigments (Faustman et al., 2010; Domínguez et al., 2019). In meat based food systems, when oxymyoglobin is converted to metmyoglobin, reactive oxygen species (superoxide anion and hydrogen peroxide) and activated metmyoglobin complexes are formed, which trigger the oxidation of unsaturated fatty acids (Domínguez et al., 2019). Moreover, some secondary products of lipid oxidation, like 4-hydroxynonenal (HNE) can promote the conversion of oxymyoglobin to metmyoglobin (Faustman et al., 2010). As the oxidation of pigments and lipids are connected, discolouration can also be observed in rancid sausages. The decline of the observed sensory properties like odour and colour occurs in a reciprocal manner (Faustman et al., 2010; Domínguez et al., 2019).

Nitrite salts, which are present in cured meat products to stabilise colour and ensure microbiological food safety, result in the formation of nitrosyl myoglobin (Suman and Joseph, 2013). Cooking is not applied in the case of sausage with paprika; therefore the conversion of nitrosyl myoglobin to nitrosyl haemachrome is not promoted. The concentration of nitrosyl myoglobin increases during the ripening/drying process of sausage, resulting in reddish colour of the final product (Acton and Dawson, 2004).

Quality decay caused by the deterioration of lipids and pigments can be perceived and also measured. Although organoleptic changes can be detected by sensory perception, there is an increasing demand for the automated instrumental evaluation of food quality. Oxidative rancidity of meat products is frequently monitored with thiobarbituric acid (TBA) test (Shahidi and Wanasundara, 2017; Domínguez et al., 2019), which measures malondialdehyde and other oxidation products that react with TBA. The result is expressed in malondialdelyde equivalents (MDA) per unit sample (Ghani et al., 2017). The colour change can be measured with a chromameter, which models human colour sensing using the CIELAB colour system. While instrumental colour measurement is rapid and non-destructive, the opposite is valid for TBA test. Because of the parallel occurrence of colour and odour defects in meat product, the question arises whether colour measurement can be used as a quick and cheap alternative for the assessment of oxidative rancidity of sausage.

Paprika (dried and ground red pepper (Capsicum sp.)) and oleoresins are popular and frequently used ingredients of sausages in Hungary. Carotenoids of red pepper are also prone to oxidation (Arimboor et al., 2015), which has to be considered when it is used as a food colourant. In sausages with paprika, the oxidation of both types of pigments (heme and carotenoids) can cause discolouration. Considering the above, the aim of this work was to observe the relationship between MDA values and CIELAB colour coordinates of a Hungarian sausage, which was sliced and then stored under refrigerated conditions for 10 weeks. 


\section{MATERIALS AND METHODS}

The fermented sausage with paprika was purchased from a local company. Proximal composition data, provided by the manufacturer, were 37 (w/w)\% fat, (15\% SFA), 21\% protein, 1.5\% carbohydrates ( $0.7 \mathrm{~g}$ sugar), $3.7 \%$ salt (sodium chloride). The product was made of pork, backfat, salt, paprika, sodium-glutamate, sodium-ascorbate, sodium nitrite, sugars (sucrose and dextrose), and starter cultures. The $45 \mathrm{~mm}$ diameter sausage bars were sliced into pieces. The weight of the slices was between 8.0 and $8.5 \mathrm{~g}$. Two slices were placed (beside each other with one side up) into one plastic storage box $(14 \times 14 \mathrm{~mm}$ width, $55 \mathrm{~mm}$ height $)$ and regarded as an experimental unit. The samples were stored under refrigerated conditions at $6 \pm 1{ }^{\circ} \mathrm{C}$ for 10 weeks. The periodic sampling during storage was achieved in triplicates, that is, three individual boxes were removed and opened and their contents were measured at each sampling occasion. Each box was sampled only once.

First the CIELAB coordinates (Carter, 2018) were determined then the TBA test was conducted on the experimental units. Instrumental colour parameters were measured as described elsewhere (Varga-Visi et al., 2017; Feki et al., 2021) on the surface of the sausage. Before the TBA assay, the sausage slices of a given box were disintegrated with a Grindomix GM 200 type grinder (Retsch $\mathrm{GmbH}$, Haan, Germany) at 10,000 r.p.m. for $5 \mathrm{~s}$. The sample $(7.0 \mathrm{~g})$ was homogenised with $100 \mu \mathrm{L}$ of 7.2 (w/v)\% BHA solution in ethanol and $20 \mathrm{~mL}$ of 5 (w/v)\% trichloroacetic acid solution using a T-25 Basic type Ultra-Turrax homogeniser (IKA Werke $\mathrm{GmbH}$ and Co. KG, Staufen, Germany) at 6,500 r.p.m. for 2 min. The suspension was centrifuged at $4,020 \mathrm{~g}$ for $10 \mathrm{~min}$ (Mikro $22 \mathrm{R}$; Andreas Hettich $\mathrm{GmbH}$ and Co. KG, Tuttlingen, Germany). In order to form the MDA-TBA adduct, aliquot of the supernatant $(2 \mathrm{~mL})$ was heated at $90^{\circ} \mathrm{C}$ for $20 \mathrm{~min}$ with $2 \mathrm{~mL}$ TBA solution $(20 \mathrm{~mm}$ TBA dissolved in $5(\mathrm{w} / \mathrm{v}) \%$ trichloroacetic acid solution). The absorbance was measured at $532 \mathrm{~nm}$ on a spectrophotometer (UV-1800; Shimadzu, Kyoto, Japan) (Ghani et al., 2017). The calibration solutions were prepared according to the method of Jung et al. (2016).

The effect of refrigerated storage on the colour parameters and MDA level were analysed with one-way analysis of variance. In case of significant difference among treatment averages, the pairwise comparison was performed with the Student-Newman-Keuls test. In case of a significant difference in group variance, the Tamhane test was used. The observed significance level ( $P$-value) used for statistical decisions was 0.05 . The relationship between the measured variables was analysed with regression analysis. The tightness of the linear fit was performed by correlation analysis. The forward method was used to decide which independent variables were included into the multivariable regression analysis model. Statistical analysis was performed using IBM SPSS Statistics 20.0 (2010).

\section{RESULTS AND DISCUSSION}

The quality of sliced sausages was quite stabile until the seventh week of storage. Neither the amount of malondialdehyde-like materials (MDA) nor most of the colour coordinates changed significantly during this time period (Table 1). Afterwards, the MDA value showed a significant increase from the seventh to the eighth week, and the level of these secondary products of lipid oxidation further increased until the end of the storage $\left(10^{\text {th }}\right.$ week). 
Table 1. Concentration of malondialdehyde equivalents (MDA) and colour coordinates in sliced sausage stored under refrigerated conditions $\left(6^{\circ} \mathrm{C}\right)$ for 10 weeks

\begin{tabular}{|c|c|c|c|c|c|c|c|c|}
\hline Storage period (week) & 0 & 2 & 3 & 4 & 5 & 7 & 8 & 10 \\
\hline MDA (mg kg $\left.{ }^{-1}\right)$ & $0.90 \pm 0.03^{\mathrm{a}}$ & $0.92 \pm 0.04^{\mathrm{a}}$ & $0.97 \pm 0.03^{\mathrm{a}}$ & $1.03 \pm 0.03^{\mathrm{a}}$ & $0.94 \pm 0.06^{\mathrm{a}}$ & $1.60 \pm 0.41^{\mathrm{a}}$ & $2.61 \pm 0.49^{\mathrm{b}}$ & $6.67 \pm 0.73^{c}$ \\
\hline $\mathrm{L}^{*}$ & $42.0 \pm 1.2^{\mathrm{ab}}$ & $39.5 \pm 0.9^{\mathrm{a}}$ & $40.3 \pm 0.6^{\mathrm{a}}$ & $40.7 \pm 1.7^{\mathrm{a}}$ & $41.8 \pm 0.8^{\mathrm{ab}}$ & $40.5 \pm 0.8^{\mathrm{a}}$ & $44.3 \pm 1.1^{\mathrm{bc}}$ & $45.1 \pm 2.0^{\mathrm{c}}$ \\
\hline$b^{*}$ & $25.1 \pm 1.3^{\mathrm{bc}}$ & $25.1 \pm 0.7^{b c}$ & $25.1 \pm 0.4^{\mathrm{bc}}$ & $25.8 \pm 1.0^{\mathrm{bc}}$ & $26.5 \pm 0.4^{c}$ & $24.4 \pm 0.7^{\mathrm{b}}$ & $23.7 \pm 0.8^{\mathrm{b}}$ & $20.8 \pm 0.3^{\mathrm{a}}$ \\
\hline $\mathrm{C}^{*}$ & $36.1 \pm 0.9^{\mathrm{cd}}$ & $35.5 \pm 0.8^{\mathrm{cd}}$ & $35.4 \pm 0.5^{\mathrm{cd}}$ & $35.4 \pm 1.1^{\mathrm{cd}}$ & $36.4 \pm 0.5^{\mathrm{d}}$ & $33.8 \pm 0.9^{c}$ & $30.8 \pm 1.2^{\mathrm{b}}$ & $25.2 \pm 1.5^{\mathrm{a}}$ \\
\hline$h^{\circ}$ & $44.0 \pm 1.6^{\mathrm{a}}$ & $45.0 \pm 0.4^{\mathrm{a}}$ & $45.1 \pm 0.2^{\mathrm{a}}$ & $46.6 \pm 0.9^{\mathrm{a}}$ & $46.7 \pm 0.1^{\mathrm{a}}$ & $46.3 \pm 0.2^{\mathrm{a}}$ & $50.4 \pm 1.8^{\mathrm{b}}$ & $55.9 \pm 4.1^{\mathrm{c}}$ \\
\hline
\end{tabular}

Values are mean \pm standard deviation $(n=3)$.

Means within row with different superscript letters are significantly different $(P<0.05)$. 
The lightness $\left(\mathrm{L}^{*}\right)$ of sausages increased significantly from the eighth week of storage (Table 1). For red-green coordinate $\mathrm{a}^{*}$, the measured values were on the positive half-axis, which measures redness. The values of this coordinate significantly decreased from the eighth week until the end of storage. For the yellow-blue coordinate $b^{*}$, the observed numbers were on the positive half-axis, which measures yellowness. The value of this parameter was significantly the lowest at the end of the storage $\left(10^{\text {th }}\right.$ week). The saturation index $C^{*}$ was quite stabile until the seventh week and showed a decline over time from the eight week having the lowest value at the end of the storage. The hue angle $h^{\circ}$ did not change until the seventh week and showed an increase in the function of time from the eighth week having the highest value at the end of the storage. The changes in these two numerically calculated values $\left(C^{*}\right.$ and $\left.h^{\circ}\right)$ depends on the variation of experimentally measured colour values. In this particular observation, the surface of the slices became less saturated, i.e. both $a^{*}$ and $b^{*}$ decreased. The colour of the surface shifted from red to yellow as the decrease of $a^{*}$ was more emphasised than that of $b^{*}$.

The development and stability of colour is a crucial quality issue in sliced meat products (Viuda-Martos et al., 2010). The observed decline in redness ( $\left.a^{*}\right)$ and yellowness $\left(b^{*}\right)$ in course of time can be attributed to the deterioration of the chromophores in meat and paprika. Fading of red colour of sausage can be connected to the oxidation of heme pigments (Faustman et al., 2010). The lipid-related co-oxidation of carotenoids derived from red pepper can also lead to colour fading. Mercadante et al. (2010) added carotenoids to sausages in order to increase their oxidative stability during a 45 -day storage at $4{ }^{\circ} \mathrm{C}$. They observed significant decrease in redness $\left(\mathrm{a}^{*}\right)$ of samples containing norbixin and lycopene, which can be attributed to the partial decomposition of those pigments while exerting their antioxidant effects. In the present study, the increase of $L^{*}$ values in the function of time might be associated also with the loss of pigments, as they decomposed, the sausages became brighter.

When the whole storage period (0-10 weeks) was considered, the level of MDA showed significant degree of association $(P<0.001)$ with each of the colour values, having the closest correlation with $a^{*}$ (Table 2$)$. Lightness $\left(\mathrm{L}^{*}\right)$ was directly, while redness $\left(\mathrm{a}^{*}\right)$ and yellowness $\left(\mathrm{b}^{*}\right)$ were inversely proportional to MDA levels.

When the two parts of the storage period were separately analysed, the degree of correlations between MDA and colour values differed between the two periods (Table 2). In the first period (0-5 weeks) the amount of MDA equivalent materials of sausages did not change significantly and it was below the value of $1.1 \mathrm{mg} \mathrm{kg}^{-1}$ (Table 1). Neither was any change in colour values measured at different weeks (Table 1). Despite of the small variation in colour and MDA values, there was a significant negative correlation $(r=-0.569 ; P<0.05)$ between MDA level and a* value in the first period $(0-5$ weeks $)$, which became more significant $(P<0.001)$ at the second period. The other two colour values $\left(L^{*}\right.$ and $\left.b^{*}\right)$ did not show significant degree of association with MDA level in the first part of storage. Therefore, it seems that loss of redness has closer relationship with MDA level than changes in brightness or yellowness.

As individual colour coordinates had relatively close correlation with MDA level, an initial multiple regression model was built:

$$
Y=\mathrm{B}_{0}+\mathrm{B}_{1} \cdot \mathrm{X}_{1}+\mathrm{B}_{2} \cdot \mathrm{X}_{2}+\mathrm{B}_{3} \cdot \mathrm{X}_{3}
$$

where $Y=$ MDA equivalent materials $\left(\mathrm{mg} \mathrm{kg}^{-1}\right) ; X_{1}=\mathrm{a}^{*} ; X_{2}=\mathrm{b}^{*} ; X_{3}=\mathrm{L}^{*}$ 
Table 2. The degree of linear relationship between the concentration of malondialdehyde equivalents $(Y)^{1}$ and the colour parameters $(X)^{2}$ in sliced sausage stored under refrigerated conditions $\left(6^{\circ} \mathrm{C}\right)$. The observed significance levels $(P)$ of the $F$-test of the regression analysis and the correlation coefficients $(r)$

\begin{tabular}{|c|c|c|c|c|c|c|}
\hline $\mathrm{X}$ & \multicolumn{2}{|c|}{$\mathrm{L}^{*}$} & \multicolumn{2}{|c|}{$a^{*}$} & \multicolumn{2}{|c|}{$\mathrm{b}^{*}$} \\
\hline Storage period (weeks) & \multicolumn{2}{|c|}{$0-10$} & \multicolumn{2}{|c|}{$0-10$} & \multicolumn{2}{|c|}{$0-10$} \\
\hline$P$ & \multicolumn{2}{|c|}{$<0.001$} & \multicolumn{2}{|c|}{$<0.001$} & \multicolumn{2}{|c|}{$<0.001$} \\
\hline$r$ & \multicolumn{2}{|c|}{$0.744^{* *}$} & \multicolumn{2}{|c|}{$-0.969^{* *}$} & \multicolumn{2}{|c|}{$-0.884^{* *}$} \\
\hline$X$ & \multicolumn{2}{|c|}{$\mathrm{L}^{*}$} & \multicolumn{2}{|c|}{$a^{*}$} & \multicolumn{2}{|c|}{$b^{*}$} \\
\hline Storage period (weeks) & $0-5$ & $7-10$ & $0-5$ & $7-10$ & $0-5$ & $7-10$ \\
\hline$P$ & 0.991 & 0.022 & 0.027 & $<0.001$ & 0.327 & $<0.001$ \\
\hline$r$ & n.s. & $0.743^{*}$ & $-0.569^{*}$ & $-0.963^{* *}$ & n.s. & $-0.955^{* *}$ \\
\hline
\end{tabular}

$Y=B_{0}+B_{1} \cdot X$.

${ }^{1} Y$ : malondialdehyde equivalents $\left(\mathrm{mg} \mathrm{kg}^{-1}\right)$.

${ }^{2} X$ : colour values ( $\mathrm{L}^{*}$ or $\mathrm{a}^{*}$ or $\left.\mathrm{b}^{*}\right)$.

${ }^{*} P<0.05 ;{ }^{* *} P<0.01 ;$ n.s. $=$ There is no significant relationship between the variables.

The regression on colour coordinates accounted for a significant portion of the variance in MDA level. However, not all colour values were incorporated into the model. When the partial effect of independent variables $\left(\mathrm{L}^{*}, \mathrm{a}^{*}\right.$, and $\left.\mathrm{b}^{*}\right)$ was investigated, their number was reduced. Only one of them, $\mathrm{a}^{*}$ value, was included into the model, as the further inclusion of $\mathrm{b}^{*}$ or $\mathrm{L}^{*}$ would not increase significantly the variance explained by the model. The regression equation was:

$$
Y=12.84+(-0.48) \cdot X
$$

where $Y=$ MDA equivalent materials $\left(\mathrm{mg} \mathrm{kg}^{-1}\right) ; X=\mathrm{a}^{*}$

The coefficient of determination of the regression model $\left(R^{2}\right)$ was 0.939 and the observed significance level $(P)$ of the $F$-test of the regression analysis was $<0.001$. That is, $93.9 \%$ of the variation in MDA level is associated with variation in the $\mathrm{a}^{*}$ value. Based on the regression coefficient of the model, if $\mathrm{a}^{*}$ value decreases with one unit, MDA level increases with $0.48 \mathrm{mg} \mathrm{kg}^{-1}$.

Based on the results it can be concluded that the relationship between MDA and colour coordinate $\mathrm{a}^{*}$ was strong. As a consequence, rapid and non-destructive colour measurement may be used to predict MDA level in case of this product. However, in case of any significant changes in the formulation, the equation has to be re-established. The observed relationship depends on each factor that exerts an effect on colour or oxidative rancidity. This is the situation when the amount or type of the fat source is modified in the recipe, because it leads to the change of the amount of unsaturated lipids prone to oxidation. Another case is when the amount of ingredients with significant antioxidant activity are altered. The change in the ratio of chromophore species also alters the relationship between colour value and MDA. The application of nitrite salts is an important factor, too. Nitrosyl metmyoglobin can be reduced in an anaerobic environment to nitrosyl myoglobin (Suman and Joseph, 2013). In sliced sausage when the partial pressure of oxygen is high in the headspace of package because the consumer who stores the package at home in the fridge opens it several times - 
the reverse reaction may occur causing discolouration. Nitrosyl myoglobin was reported not to act as a catalyst of fatty acid oxidation (Harms et al., 2003). Nevertheless, further research is needed to clarify whether the observed correlation between colour and MDA has any connection with the deterioration of heme pigments containing nitric oxide in cured meat products.

The detected increase of MDA level was caused by lipid oxidation under storage of sausage. Lipid oxidation follows different mechanisms in intact biological systems than in disintegrated food systems. In maintained cellular structures like meat, the ratio of unsaturated fatty acids is higher in membrane lipids than in cytosolic triglyceride droplets, therefore, lipid oxidation is mainly membrane associated process (Domínguez et al., 2019). When sausages are processed, a significant part of the cell structure is disrupted. The surface of the resulting fat globules is covered with proteins and amphipathic membrane lipids. Proteins and phospholipids have negative charge, therefore, they concentrate the transition-metals to the interface of the emulsion (Mercadante et al., 2010). Transition-metal ions can initiate lipid oxidation via Fenton reaction (Domínguez et al., 2019). Carotenoids are situated, depending on their polarity, close to the interface or inside of the fat globules (Mercadante et al., 2010). These yellow, red, or orange colour compounds can react with the intermediate products of lipid oxidation (Arimboor et al., 2015) and their decomposition can led to discolouration. That is, the background of the observed strong relationship could be that lipid oxidation and pigment degradation share common pathways at the same locations in the microstructure of sausage.

\section{CONCLUSIONS}

The observed correlation between MDA level and colour coordinates supports the assumption that the relationship is significant between the oxidation of lipids and pigments in the case of sausage with paprika.

Rapid and non-destructive colour measurement may be used for the assessment of the oxidative degradation processes. However, the degree of relationship between colour values and MDA may vary from product to product, as it depends on all factors governing lipid oxidation and level of chromophores.

\section{ACKNOWLEDGEMENT}

This work was supported by project "EFOP-3.6.3-VEKOP-16-2017-00005" co-funded from the Hungarian State.

\section{REFERENCES}

Acton, J.C., and Dawson, P.L. (2004). Impact of proteins on food colour. In: Yada, R.Y. (Ed.), Proteins in food processing. Woodhead Publishing, pp. 631-668. 
Arimboor, R., Natarajan, R.B., Menon, K.R., Chandrasekhar, L.P., and Moorkoth, V. (2015). Red pepper (Capsicum annuum) carotenoids as a source of natural food colors: analysis and stability - a review. Journal of Food Science and Technology, 52(3): 1258-1271.

Carter, E.C., Schanda, J.D., Hirschler, R., Jost, S., Luo, M.R., Melgosa, M., Ohno, Y., Pointer, M.R., Rich, D.C., Viénot, F., Whitehead, L., and Wold, J.H. (2018). CIE015:2018 Colorimetry 4th ed. International Commission on Illumination (CIE).

Domínguez, R., Pateiro, M., Gagaoua, M., Barba, F.J., Zhang, W., and Lorenzo, J.M. (2019). A comprehensive review on lipid oxidation in meat and meat products. Antioxidants, 8: 429. 1-31.

Faustman, C., Sun, Q., Mancini, R., and Suman, S.P. (2010). Myoglobin and lipid oxidation interactions: mechanistic bases and control. Meat Science, 86: 86-94.

Feki, A., Sellem, I., Hamzaoui, A., Amar, W.B., Mellouli, L., Zariat, A., Nasri, M., and Amara, I.B. (2021). Effect of the incorporation of polysaccharide from Falkenbergia rufolanosa on beef sausages for quality and shelf life improvement. LWT - Food Science and Technology, 143: 111-139.

Ghani, M.A., Barril, C., Bedgood, D.R. Jr, and Prenzler, P.D. (2017). Measurement of antioxidant activity with the thiobarbituric acid reactive substances assay. Food Chemistry, 230: 195-207.

Harms, C., Fuhrmann, H., Nowak, B., Wenzel, S., and Sallmann, H.P. (2003). Effect of dietary vitamin E supplementation on the shelf life of cured pork sausage. Meat Science, 63: 101-105.

Jung, S., Nam, K.C., and Jo, C. (2016). Detection of malondialdehyde in processed meat products without interference from the ingredients. Food Chemistry, 209: 90-94.

Mercadante, A.Z., Capitani, C.D., Decker, E.A., and Castro, I.A. (2010). Effect of natural pigments on the oxidative stability of sausages stored under refrigeration. Meat Science, 84(4): 718-726.

Shahidi, F., Wang, J, and Wanasundara, U.N. (2017). Methods for measuring oxidative rancidity in fats and oils. In: Akoh, C.C. (Ed.), Food lipids: Chemistry, nutrition, and biotechnology. CRC Press, Boca Raton, pp. 519-542.

Suman, S.P., and Joseph, P. (2013). Myoglobin chemistry and meat color. Annual Review of Food Science and Technology, 4: 79-99.

Varga-Visi, É., Toxanbayeva, B., Andrássyné Baka, G., and Romvári, R. (2017). Organoleptic quality of reduced fat Turkey sausage using pea fiber or potato starch additives. Acta Agraria Kaposváriensis, 21: 53-59.

Viuda-Martos, M., Ruiz-Navajas, Y., Fernández-López, J., and Pérez-Álvarez, J.A. (2010). Effect of orange dietary fibre, oregano essential oil and packaging conditions on shelf-life of bologna sausages. Food Control, 21: 436-443.

Open Access. This is an open-access article distributed under the terms of the Creative Commons Attribution 4.0 International License (https://creativecommons.org/licenses/by/4.0/), which permits unrestricted use, distribution, and reproduction in any medium, provided the original author and source are credited, a link to the CC License is provided, and changes - if any - are indicated. (SID_1) 